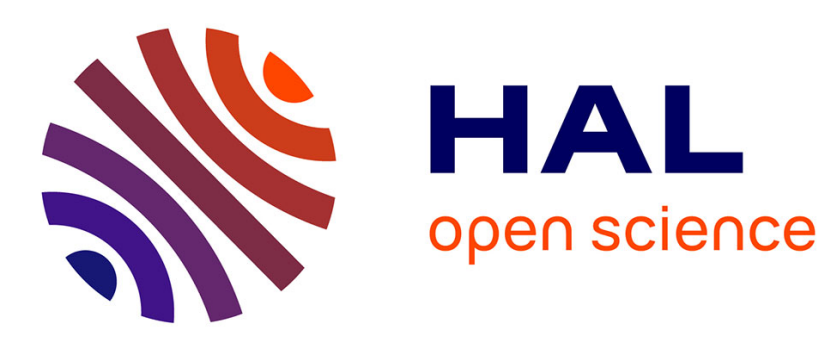

\title{
The King Island Digital Stories (KIDS) Project: Telling Stories for Tomorrow's Learning
}

Jennifer Masters

\section{To cite this version:}

Jennifer Masters. The King Island Digital Stories (KIDS) Project: Telling Stories for Tomorrow's Learning. 11th IFIP World Conference on Computers in Education (WCCE), Jul 2017, Dublin, Ireland. pp.199-208, 10.1007/978-3-319-74310-3_22 . hal-01762862

\section{HAL Id: hal-01762862 \\ https://hal.inria.fr/hal-01762862}

Submitted on 10 Apr 2018

HAL is a multi-disciplinary open access archive for the deposit and dissemination of scientific research documents, whether they are published or not. The documents may come from teaching and research institutions in France or abroad, or from public or private research centers.
L'archive ouverte pluridisciplinaire HAL, est destinée au dépôt et à la diffusion de documents scientifiques de niveau recherche, publiés ou non, émanant des établissements d'enseignement et de recherche français ou étrangers, des laboratoires publics ou privés. 


\title{
The King Island Digital Stories (KIDS) Project: Telling Stories for Tomorrow's Learning
}

\author{
Jennifer Masters \\ Faculty of Education, University of Tasmania, Australia \\ jennifer.masters@utas.edu.au
}

\begin{abstract}
The King Island Digital Stories (KIDS) project was an initiative to extend children's literacies through developing digital stories. The project was conducted over a ten-week term with 21 children in a Year 4/5 class. An ethnographic approach was used where the research team worked collaboratively in the classroom to scaffold individual children to represent their story ideas. The children were told that their stories needed to be about King Island and in their voice (first person) but otherwise, the stories could be about any aspect. The project was slow to start but a weekly sharing session helped the children to conceptualise and develop their stories. As the resources began to emerge, it was evident that the children were engaging effectively with the process of digital storytelling and developing their literacies, especially digital literacies. The resulting digital stories were diverse but collectively they communicated a tapestry of life on the island through the children's eyes.
\end{abstract}

Keywords. digital storytelling, literacies, digital literacies, sense of place

\section{Introduction}

The King Island Digital Stories (KIDS) project focused on King Island, an isolated island in the middle of Bass Strait, and the children who live there. The children at the local school benefit from living in a unique and pristine setting but are disadvantaged by their isolation and lack of connection with the wider world. The purpose of this project was to harness digital technologies in order to enable these children to represent their ideas and perspectives about their own place to share with a wider audience. Through this process the children learnt how to use technologies for communication and developed their literacies by preparing content for an audience as they articulated their understandings through the medium of digital storytelling.

\section{Background}

A 'digital story' is a short media production that is created with digital tools to present stories about life, place or personal perspectives. This genre of communication is linked to traditions of oral storytelling [1] and is readily accessible to ordinary people, in contrast with commercial or professional productions. Digital storytelling emerged in the 1990s [2] when suitable digital tools became available and affordable to the wider population and early adopters included educators, who were quick to connect 
with this medium as a way to engage children in learning. A significant benefit of using digital storytelling for teaching and learning is that it extends the concept of literacy. Sylvester and Greenidge [3] identified that digital storytelling promotes the development of 'emerging literacies' in addition to traditional literacies, that is, reading, writing, speaking and listening. Lankshear and Knobel [4] referred to these new literacies as 'digital literacies' and highlighted the plurality of the term. They proposed that the term encompassed a wide range of skills, techniques and approaches for using digital communication, including the capacity to adapt for new mediums as they emerge. Sylvester and Greenidge [3] suggested that digital storytelling could be used to extend children who found writing difficult. When presented with a less textorientated form of communication, with audio and image, children were more motivated to create stories. Further, the process of 'polishing' their media production allowed these children to review and adjust until they were comfortable that their work was ready to share. Other researchers, for example, Di Blas, Paolini and Sabiescu [5] highlighted that digital storytelling also allows for collective construction where children work together to produce a collaborative production. In this process children learn to construct narrative in a social way, through negotiation and reciprocal sense making.

Another powerful feature of digital storytelling is that it gives voice to people who don't often get to tell their stories. The stories might be about characters, journeys, locations or accomplishments but they are always told from a particular perspective and in the voice of the storyteller [2]. Emert [6] used digital storytelling to facilitate refugee children tell their stories and demonstrate their skills at storytelling in a tangible way. He asserted that "the opportunity to transform personal stories through visual media is particularly powerful for a population of learners whose life histories are marred by tragedy" (p. 401). Digital storytelling is also seen as an effective way to support Indigenous people to articulate their stories and promote their culture and a number of initiatives have been implemented with Australian Indigenous children. For example, the SWIRL program [7] was established in 1998 and is an ongoing project that connects pre-service teachers with remote communities to promote literacy and storytelling for young Indigenous children. Another project of this style is the Sharing Stories Digital Storytelling Program [8]. The Sharing Stories Foundation's charter is to protect and promote Aboriginal and Torres Strait Island cultures and languages and the Digital Storytelling Program provides workshops in Indigenous communities to facilitate young people to tell their stories. A common feature of this type of digital storytelling is the representation of place attachment, also known as "sense of place" [9]. This acknowledges that all stories are in a context and therefore they not only represent ideas and perspectives but are likely include a component of belonging and connection to the physical space.

The process of digital storytelling is highly personalised and therefore it is essential that the storyteller is empowered to build his or her own representation rather than being prescribed a formula for construction. This, however, doesn't mean that the teacher is redundant in the process. In fact, Ohler [10] suggested that the opposite is more likely, with the student needing careful guidance and advice throughout the process. In this circumstance, the teacher uses a process called scaffolding [11] to work with the storyteller to provide just-in-time support to use digital technologies to bring their story to fruition. In this study, the research team worked in this role to 
support children developing digital stories. This allowed the teachers in the classroom to watch how children could build their stories and how this in turn could support the development of digital literacies.

\section{Method and Design}

This research used an ethnographical approach in which the researcher was an "active participant-observer [12]. This approach is often used when a project has a cultural focus and in this study it allowed the research team to participate in the project alongside teachers to provide support and expertise as the children work with digital technologies to create their stories.

The goals for the research project were to investigate how the children could:

- Work with digital technologies to create digital stories

- Develop their skills in digital literacies

- Enhance their communication skills through creating situated digital stories

- Create stories about sense of place and belonging

The research question for the study was:

How might digital stories about place be used to support children in a remote setting to develop literacies, digital literacies and communication?

The King Island Digital Stories (KIDS) project was funded through a Tasmanian Community Fund grant for $\$ 20,000$ (AUD). This provided technological equipment such as tripods, cameras and software and enabled a project research officer to be employed to work with the children. The project was implemented in a Year 4/5 class at King Island District State High School. The class consisted of 21 children, 14 in Year $4($ age $\approx 10)$ and 7 in Year 5 (age $\approx 11)$. Two teachers taught the class as a team, with additional support staff at times. The project commenced at the end of Term 3 and the digital story production was implemented in the final term of the school year (Term 4). This provided approximately ten weeks for creating the digital stories.

While the term "digital storytelling” is often used in education as a blanket term for any sort of digital production, for example, retelling fairy tales or developing fantasy, this project aligned with a narrower, more traditional concept of digital storytelling described by Joe Lambert from the StoryCenter [2]. In this context, a digital story tells a non-fiction narrative from a personal perspective. Further, while it is possible to use snips of video footage, a digital story is typically a collection of still images that is animated through transitions and includes a music soundtrack and an oral narration. The children in this study were told that their story needed to be real and in first person, with their 'voice'. It also needed a beginning, a middle and an end (so that it was a story) and it had to be about King Island. Their task was to develop a storyline and a script, collect images to illustrate their story, record their narration and decide on a music soundtrack and then put the digital story together using iMovie.

\section{Findings}

In the preparatory session at the end of Term 3, the children were asked to write a story about King Island using a 'story starter' card, depicting images such as local 
flora and fauna, history, pastimes or industries. They were told that their story should be realistic rather than fantasy and they should select an image that would remind them of something that happened to them, something they did or something that they were told about, as long as it was about King Island. The children were provided with a story sheet and were given 40 minutes to complete the task. These stories were used as a base writing assessment and revealed that the writing capacity of the children in the class varied considerably. While some children managed to fill two pages with a detailed story, others were struggling to write a sentence or two with considerable help from the teacher or a teacher aide.

The digital storytelling development commenced at the beginning of Term 4. The children were shown plenty of examples of digital storytelling. Some of these were sourced from online repositories, such as ABC Open (https://open.abc.net.au/) and the research team also made some example digital stories to model aspects such as focus on place, timing, voice and techniques, for example, transitions and green-screen methods. The children were given plenty of time to think about and talk about their digital story idea. A 'story circle' technique [2] was used to help children articulate their storyline. This process enabled individuals to flesh out their own story and it inspired others who were still struggling to develop their own story idea.

The students were each provided with a planning book to document their digital story. This book had room for brainstorming ideas, making lists of resources, writing a script, storyboarding the digital production and reflecting on the task. At the beginning of the term, the children worked on their digital story as part of their literacy sessions. These sessions were two mornings per week and the digital story was one of several tasks that the children could choose to work on. When they undertaking the digital story activity, the children could work independently or they could seek the help of the research team. Conversely, the two researchers would seek out individual children during this session to check on progress and encourage them to do more.

The researchers monitored each child's progress with a milestone checklist. After a few weeks in to the project, it was evident that while most children had spent time working on the digital story, not a lot of advancement had been made. The children had plenty of good ideas for stories and many had written a story plot but very few had started on the 'digital' component of the story. One sticking point seemed to be the sourcing of digital images. The children had iPads, a digital camera and a Go-Pro camera that they could borrow to capture images for the project. Further, most of them had access to a smart phone at home that they could use too. It seemed though that most of the images for the stories needed to be existing rather than created afresh and families didn't seem to have catalogued collections of images. The children had access to a USB stick to take home to collect images but these often came back with no images at all or only a few images, often of limited quality. Some of the children reported that they had a particular image that they wanted to use but it was on a device other than a computer and that they didn't know how to transfer it to a USB.

In order to overcome these impediments, it was decided to focus on a few of the more advanced stories to see if some completed digital stories might act as motivation for the other children. Two children, a boy and a girl, had managed to find a selection of photographs for their stories and so these two were used as pilot productions. The boy told a story was about rearing a baby kangaroo, while the girl told the story of her 
parent's wedding at Cape Wickham Lighthouse, the tallest lighthouse in Australia. These two stories were fast-tracked through production, with the boy volunteering to pioneer a green-screen narration. Although these first digital stories were only prototypes and rather hurried, they certainly had the desired effect. The two productions were shown to the class and the rest of the children were very impressed. There were many questions about the creation process and certainly a renewed interest in pushing ahead with the stories. Based on this outcome, it was decided that this strategy would be incorporated into the project. Rather than working through the stages systematically with all of the children in the class, two or three children were targeted for production at a time. This helped to 'spread the field' across the production steps, so some children might be still typing up their scripts, while others were preparing images, recording their narration, choosing music or compiling their digital stories in iMovie. The Monday literacy session became a regular sharing event where a few 'first cut' productions were shown to the rest of the class each week.

The advantages of this trickle strategy were multiple. Firstly, while the researchers still monitored the whole class for progress, they could dedicate blocks of time to work with a few children. This meant that a digital story could be constructed quite quickly and move from being a collection of media to a compiled video in a few hours. Not only did this provide fresh examples for children still working on their stories but it also meant that children who had completed the process could act as mentors for the other children. This was particularly beneficial for tentative children who were finding the process of recording 'talking head' footage with a green screen or even a simple voice recording quite intimidating. A further benefit was that there was less demand on the equipment at any given time. Further, children who completed their story earlier then had time to review and 'polish' their production before the end of term.

A disadvantage of this method, however, was that some children had to wait quite a few weeks before they got to work seriously on their production. This, conversely, could be seen as advantageous because it meant that children who were reluctant or procrastinating initially, had time to become interested in the project. Children who were at first not overly captivated in the process became more curious when they saw the success of their peers. The emerging examples were constant reminders of what could be achieved and then, if a child became desperate to complete their own story, they could usually be slotted in to the schedule quite quickly. While this delay may have potentially led to some children losing interest in their production, this was not the case in the study. The momentum built consistently over the term and by the week of the presentation all of the children had a story that they were keen to share.

It was interesting to note that this change in approach seemed to coincide with shift in the ownership of the stories [11]. In the initial stages, the digital story was one of several tasks that the children did during the literacy session. The children worked on the story because their teacher had listed it as a literacy task and/or the researchers suggested to a child that he or she should work on a component. As the project progressed, however, it was evident that all of the children in the class became more outcome focused and took on the responsibility of reaching milestones and completing stages. This, in turn, influenced how the project was implemented. Rather than just attending the literacy sessions, the researchers made themselves available to the children as much as possible, attending most days and working with individuals in 
a breakout room in tandem with other classroom activity. Instead of having to remind children to work on their story, it was more likely that a child would seek out the researchers, saying "I have this to do. Can you help me?"

Digital media production in the classroom is usually implemented with a documentation process where the children record their ideas and storyline with a storyboard [10]. This project followed this convention and, as identified previously, the children were provided with a bound storytelling book to document their progress. This book was useful in the initial stages when the children were recording ideas and writing a script but as soon as the production became visual, ie, when the children started to select and collect images, the book seemed redundant. The images were collected and displayed on a computer or device, such as an ipad or ipod and the children browsed through them. When the child selected the images they wished to use, they were saved to the child's project folder. The most obvious next step was to drag the images into the timeline on iMovie and arrange them there. The idea of going back and storyboarding on paper didn't seem logical. Consequently, the children mostly didn't use the storyboarding chart provided in their project book.

Typically, digital media production in a classroom is completed as group work. There are several practical reasons for this. Firstly, it caps the number of productions that are completed. This means that the equipment is in less demand and the teacher has fewer projects to manage. It also gives children experience with collaborative creation where negotiation and cooperation are required. In this project, however, the digital stories were produced individually. To some extent, this was because project adopted the classic form of digital storytelling [2] where the storyteller provides a narrative from his or her own perspective. This direction in the project also related the focus on personal writing and literacy. Additionally, the funded project officer meant that children could receive personalised support. While this ratio would be a luxury in most classrooms, the project provided a rare opportunity to observe how an individual child can harness digital technology to express their own ideas with personalised scaffolding.

Whilst the children didn't create joint digital stories for the project they still engaged in plenty of social collaboration and this increased throughout the project. During the sharing sessions there was authentic and enthusiastic discussion about the productions. Often the discussion was about technical aspects but there was also conversation about story plots and creative features. One girl's story was about watching the fairy penguins return to the shore at dusk and her oral narration had impressive 'David Attenborough' tones. The other children picked this up immediately and copied the style in their chat about the production. This sense of play helped to highlight the very feature that made the story so effective.

There was also a strong social component to the digital production process. Although the researchers usually worked with individuals in a breakout area, it was not uncommon for other children to wander through, watch and contribute during this process. This was not discouraged and it soon became a valuable strategy for reflection and critical decision making. Further, as children completed their digital stories, they could in turn serve as valuable mentors for other who were still to undertake stages in production. So, even though the stories were not a group task, the children in the class experienced similar circumstances where negotiation and cooperation were needed. The difference in this case, however, was that each child 
was firmly the owner of their own story, and they would decide when advice or support from others would be applied.

The presentation of the digital stories to family and friends at the end of term was a natural focus for story production. Towards the end of term, activity became brisk as the finishing touches were put in place. The children created invitations that were posted to families and the teacher planned an afternoon tea that was prepared by the children before the presentation and then served after the event. The presentation was held in the school's auditorium and was extremely well attended. The sense of pride felt by the children, their families and the school was clearly apparent. A selection of the digital stories was also shown at the school's awards night later in the week. The children and their families were then asked for permission for the digital stories to be published on the project website. The website is available at www.kidsproject.net.au and is a lovely representation of the project journey and the children's understandings of sense of place.

\section{Discussion}

Being an active participant-observer in a study such as this provides a wonderful opportunity to reflect on teaching and learning using digital technologies. Some key reflections are presented here in light of the findings.

\subsection{Task progression}

It is not easy to prescribe a lesson sequence for a project such as this. Instead, it is more realistic to have a good idea about the destination and then set off on the learning journey. In the beginning of the project a number of strategies were used to help the children conceptualise what they might tell a story about and this included outlining a basic scope, showing a wide range of examples and providing plenty of opportunities to talk about what they might create. It is actually difficult to do much more than this until the storyteller decides on the story and commits to the creation process. Then, once he or she has this ownership, it is relatively straight forward to support and encourage them. In this project, we needed to reach that 'tipping point' where some of the children are engaged with the task and forging ahead with their production. Once this happens, the other children see the process in action and are more likely to follow. Needless to say, this progression needs patience and takes time. While it is desirable to have a defined end point in sight, that is the presentation, it is essential that children are given extended time, weeks not days, in order to allow their stories to develop.

\subsection{Sourcing Images}

The realisation that children were having difficulties in bringing images from home came as quite a surprise. These children are growing up in the digital age and digital photographs are a common and frequent occurrence in their daily lives. It became evident though that while families take copious digital photographs of children, they are less likely to store and catalogue them. Many of the photos taken are for immediate consumption, either viewed directly on a smart phone, emailed to family 
and friends or posted on Facebook. Relatively few of these images are transferred to a computer to be stored for prosperity. Further, if families do have images on a computer or another storage device such as a USB then they are often difficult to find as they aren't catalogued or named systematically for searching. Additionally, when the children managed to find images that they wanted to use they often found it difficult to transfer them on to a USB. This could be because the format wasn't compatible (eg. it could be on an iPod) or that they simply didn't know how to copy it to the drive. Further, quite a few of the images that were brought in were of dubious quality for digital story production. They were of low resolution, opportunistic rather than framed or in portrait rather than landscape orientation.

As the project progressed it became evident that quality images were going to mean the difference between good digital stories and a great digital stories. The children were encouraged to progressively accumulate a good collection of potential images to be stored in personalised folder. These included existing photos and also new photos taken for the project. The children were given tips on taking photos, such as using landscape orientation and considering the position of the sun. Some of the existing photos were cropped to change the orientation and framing. The researchers also developed an image bank of local pictures that could be used to supplement the children's image collections. This ensured that when the child selected images for their story they could afford to be discerning as they had plenty to choose from.

\subsection{Documentation}

As identified in the Findings section, the paper-based planning books provided for each child became peripheral during this study. This was interesting because most advice provided for teachers identifies that the storyboarding process is a critical component of digital storytelling [10]. It would have been possible to insist that the children used the book, even if the storyboard was contrived after the event, but it was decided that this was unnecessary, especially as most of the children seemed to retain a good grasp of their storyline from the display in the iMovie. This observation may indicate that learners in the digital age are truly moving away from paper and pencil planning. It may, however, have only worked in this case because of the individualised nature of this task. It was possible to do this with a single child but if the task had been a group effort where content negotiation was needed then a documented storyboard may have been a necessary step.

\subsection{Managing Digital Storytelling in the Classroom}

This project offered the luxury of having two experienced media developers to provide scaffolding for the children as they created digital stories. It isn't surprising, therefore, that the outcome of the project was a collection of imaginative and effective digital stories. One of the project classroom teachers was asked by other teachers if she could have implemented the storytelling activity without the project backing. She identified that she could see how effective it was but conceded that it would have been too difficult to implement without the support. This is completely understandable and explains one of the reasons why teachers who embark on digital media construction usually do opt for group productions. There are, however, some other strategies illustrated in this study that will help to facilitate sustainable digital 
media production in any classroom. In particular, the concept that it is possible for some children to move ahead with the process without have to ensure the whole class meets the same milestones in the same time is useful. This would mean that a teacher could work with a few students initially and then she or he would have experienced helpers to work with the remaining students. Another outcome of this study is that the children who participated in this project now have considerable skills in digital media production. Any work they do in future will be influenced by this experience and it is likely that they will be able to achieve similar outcomes without the careful scaffolding. Further, they will be able to work with other students who are novice learners in this area and their digital stories produced as part of this project will be tangible examples for other children.

\subsection{Digital storytelling and literacy}

This project started with asking the children to write a story using traditional paperbased methods, in a similar format to the national NAPLAN writing tests [13]. This material provided a useful starting point for the project and a benchmark for generic literacy standards. It wasn't appropriate, however, to simply compare this text against the scripts written for digital stories, in an attempt to look for some sort of progression. It was clearly evident that the definition of literacy needed to be far wider for this task and had to include multimodal aspects such as visual, oral, audio and information literacies, as well as digital literacies. The children in the classroom already had access to appropriate digital technologies including a few class computers and an iPad each. The additional technologies introduced with this project complemented the classroom resources and provided a good range of tools for digital storytelling purposes. Although most of the children hadn't attempted digital production before they were certainly ready to use these tools. They engaged willingly with the technical tasks such as writing scripts in Word, taking photographs with their iPads or the digital cameras provided, recording voiceovers with ipads or in the green screen studio and then using iMovie for video production. Perhaps the most important impact that the project had on the children's literacy wasn't learning the technical skills in isolation but experiencing the use of digital technologies driven by purpose. The digital story project provided a real context where the technology was used creatively to communicate their story about place to an authentic audience.

\section{Conclusion}

Digital storytelling incorporates 'old' literacies - writing, speaking, reading and listening - with 'new' literacies or digital literacies where learners use digital technologies as a medium to tell their stories. The King Island Digital Stories Project supported the children on King Island to engage with this process as they created stories about their 'place', a remote and beautiful island between mainland Australia and Tasmania. The Year 4/5 children not only learnt the technological skills for media production but they also learnt about harnessing technology for creative and communication purposes. It is anticipated that this experience will facilitate their engagement with literacies and help them to use technologies more effectively for tomorrow's learning. 
Acknowledgments. The author would like to thank the Tasmanian Community Fund for funding the KIDS project.

\section{References}

1. Porter, B.: DigiTales: The Art of Telling Digital Stories. Bernajean Porter Consulting, Denver, CO (2005).

2. Lambert, J.: Digital Storytelling: Capturing Lives, Creating Community (4th Ed.). Routledge, New York (2013)

3. Sylvester, R., Greenidge, W.: Digital storytelling: Extending the potential for struggling writers. The Reading Teacher. 63 (4), 284-295(2009)

4. Lankshear, C., Knobel, M.: Digital Literacies: Concepts, Policies and Practices. Peter Lang, New York (2008)

5. Di Blas, N., Paolini, P., Sabiescu, S.: Collective digital storytelling at school as a wholeclass interaction. In Proceedings of the 9th International Conference on Interaction Design and Children, 11-19 (2010)

6. Emert, T.: Interactive digital storytelling with refugee children. The Language Teacher. 91(6), 401-415 (2014)

7. Mahon, L.: Story writing in remote locations: Authoring culturally appropriate literature with children. In Yelland, N., Neal, G., Dakich, E. (eds.) Rethinking Education with ICT: New Directions for Effective Practices. Sense Publishers, Rotterdam (2008).

8. Sharing Stories Foundation: Sharing Stories. Retrieved from http://sharingstories.org/ (2014)

9. Avriel-Avni. N., Spektor-Levy, O., Zion, M., Rosalind-Levi, N.: Children’s sense of place in desert towns: A phenomenographic enquiry. International Research in Geographical and Environmental Education. 19(3), 241-259 (2010)

10. Ohler, J.: Digital storytelling in the classroom: New Media Pathways to Literacy, Learning and Creativity. Corwin, Thousand Oaks (2013)

11. Masters, J.: Teachers Scaffolding Children Working with Computers: An Analysis of Strategies. VDM, Saarbrucken, Germany (2008)

12. Johnson, J., Avenarius, C., Weatherford, J.: The active participant-observer: Applying social role analysis to participant observation. Field Methods. 182, 111-134 (2006)

13. Australian Curriculum, Assessment and Reporting Authority (ACARA): NAPLAN. Retrieved from https://www.nap.edu.au/naplan (2016) 